\title{
Integration of the antennal lobe glomeruli and three projection neurons in the standard brain atlas of the moth Heliothis virescens
}

\author{
Bjarte Bye Løfaldli, Pål Kvello and Hanna Mustaparta* \\ Neuroscience Unit, Department of Biology, Norwegian University of Science and Technology, Trondheim, Norway
}

Edited by:

Randolf Menzel, Freie Universitat

Berlin, Germany

Reviewed by:

Joachim Schachtner, Philipps-

Universitat Marburg, Germany

Uwe Homberg, Philipps-Universitat

Marburg, Germany

${ }^{*}$ Correspondence:

Hanna Mustaparta, Neuroscience Unit,

MTFS, Department of Biology,

Norwegian University of Science and

Technology, Olav Kyrres gt. 9, 7489

Trondheim, Norway.

e-mail: hanna.mustaparta@bio.ntnu.no
Digital three dimensional standard brain atlases (SBAs) are valuable tools for integrating neuroimaging data of different preparations. In insects, SBAs of five species are available, including the atlas of the female Heliothis virescens moth brain. Like for the other species, the antennal lobes (ALs) of the moth brain atlas were integrated as one material identity without internal structures. Different from the others, the $H$. virescens SBA exclusively included the glomerular layer of the AL. This was an advantage in the present study for performing a direct registration of the glomerular layer of individual preparations into the standard brain. We here present the $H$. virescens female SBA with a new model of the AL glomeruli integrated into the atlas, i.e. with each of the 66 glomeruli identified and labelled with a specific number. The new model differs from the previous $H$. virescens $A L$ model both in respect to the number of glomeruli and the numbering system; the latter according to the system used for the $A L$ atlases of two other heliothine species. For identifying female specific glomeruli comparison with the male AL was necessary. This required a new male AL atlas, included in this paper. As demonstrated by the integration of three AL projection neurons of different preparations, the new SBA with the integrated glomruli is a helpful tool for determining the glomeruli innervated as well as the relative position of the axonal projections in the protocerebrum.

Keywords: insect, olfaction, three dimensional reconstruction, mushroom body calyces, lateral protocerebrum

\section{INTRODUCTION}

Digital three dimensional standard brain atlases (SBAs) have been made of several vertebrate and insect species in order to integrate neuroimaging data of different preparations (Toga and Thompson, 2001; Rein et al., 2002; Toga, 2002; Van Essen, 2002; Brandt et al., 2005; Kurylas et al., 2008; el Jundi et al., 2009; Kvello et al., 2009). In insects, whole brain atlases of five species are available as suitable tools for studying the three dimensional spatial relationship between neurons innervating different brain structures (Rein et al., 2002; Brandt et al., 2005; Kurylas et al., 2008; el Jundi et al., 2009; Kvello et al., 2009). Based on confocal scans with higher resolution, separate atlases of specific brain compartments like the primary olfactory centre, the antennal lobe (AL), and the central complex involved in processing visual information, have also been made (Rospars and Chambille, 1981; Flanagan and Mercer, 1989; Stocker et al., 1990; Galizia et al., 1999; Laissue et al., 1999; Rospars and Hildebrand, 2000; Chiang et al., 2001; Berg et al., 2002; Reischig and Stengl, 2002; Sadek et al., 2002; Smid et al., 2003; Greiner et al., 2004; Huetteroth and Schachtner, 2005; Masante-Roca et al., 2005; Skiri et al., 2005; Iyengar et al., 2006; Jefferis et al., 2007; Kazawa et al., 2009; Varela et al., 2009; el Jundi et al., 2010). Thus, the neurons can be registered into these particular structures with higher precision, suitable for studying the network within the brain compartments. Recently, we have made a SBA of Heliothis virescens based on the iterative shape average (ISA) procedure, with the aim to spatially relate identified neurons forming the networks underlying chemosensory coding and learning in this moth species (Kvello et al., 2009). Like for all five insect brain atlases, the ALs are included as a single brain compartment without internal structures. Different from the other atlases, the $\mathrm{AL}$ of the $H$. virescens brain atlas includes exclusively the glomerular layer as a single labelled identity, an advantage for registering the AL glomeruli as separate units into the atlas.

Numerous studies have been devoted to the neuronal network of the primary olfactory centres, the olfactory bulb in vertebrates and the AL in insects, in trying to elucidate how olfactory information is processed and coded (Laurent et al., 1996; Hildebrand and Shepherd, 1997; Galizia and Menzel, 2000; Lledo et al., 2005; Wilson and Mainen, 2006; Stopfer, 2007; Kloppenburg and Mercer, 2008). Common for the two systems are the input elements of sensory neurons, the output elements of mitral/tufted cells and projection neurons (PNs) respectively, intrinsic local interneurons, as well as centrifugal modulatory neurons. Typical are the numerous glomeruli, spheric-ovoid structures of fine neuropils with condensations of synapses forming a neuronal network; in insects between all four elements. Each glomerulus represents a functional unit receiving information from one set of sensory neurons with the same receptor protein type and sending out the processed information to olfactory areas of higher order (Axel, 1995; Clyne et al., 1999; Vosshall et al., 1999; Buck, 2000; Mombaerts, 2001; Vosshall and Stocker, 2007). In insects, the output neurons are unior multiglomerular PNs with axons following one of three major 
antennocerebral tracts, the inner (IACT), the middle (MACT) and the outer (OACT) in moths (Homberg et al., 1988; Rø et al., 2007). They project to the calyces of the mushroom bodies, important in learning and memory (Menzel, 2001; Heisenberg, 2003), and to the lateral protocerebrum, a premotoric area. To resolve how biologically relevant odour information is handled by the network, it is essential to determine the relevant input and output of specific glomeruli, which also require identification of the glomeruli across individuals. The atlases of the AL glomeruli of several insect species including heliothine moths have supported the early findings of constant numbers and positions. Thus, they are helpful tools in identifying the glomeruli innervated by physiologically characterised AL neurons.

In herbivorous species of Lepidoptera the $\mathrm{AL}$ is organised into two parallel olfactory systems, the macroglomerular complex (MGC) consisting of a few glomerular units dealing with pheromone information in male moths, and the numerous ordinary glomeruli dealing with plant odours in males and females (Anton and Homberg, 1999; Christensen and Hildebrand, 2002; Mustaparta, 2002). Due to available, identified pheromone components as well as the relative simple system, the functional organisation of the MGC is to a large extent resolved in several species, including $H$. virescens, as concerns input and output information (Berg et al., 1998; Vickers et al., 1998; Anton and Hansson, 1999; Galizia et al., 2000; Kanzaki et al., 2003; Vickers and Christensen, 2003). Knowledge about the more complex plant odour system is in general scarce, partly due to unknown relevant plant odorants. However, using chemical analyses linked to electrophysiological recordings from single units, sharply tuned plant odour receptor neurons have been well documented, particularly in $H$. virescens for which numerous primary and secondary plant odorants have been identified (Mustaparta and Stranden, 2005; Røstelien et al., 2005). These results are important in ongoing studies on the processing of plant odour information in the brain of this species. Using intracellular recordings combined with fluorescent staining we are physiologically characterising chemosensory neurons, including PNs, followed by visualisation in confocal laser scanning microscope and three dimensional reconstructions (Rø et al., 2007; Kvello et al., 2009). The neurons are subsequently registered into the SBA for spatially relating the neurons from different preparations in this common frame. In order to identify the PNs it is important to determine the glomeruli they innervate. This may be performed using the separate AL atlas. However, in order to relate the glomeruli giving input to the PNs with their output regions in protocerebrum, integration of the $\mathrm{AL}$ glomeruli into the SBA is required.

In this paper we present the $H$. virescens female SBA with a new model of the AL glomeruli integrated into the atlas (SBAGl), i.e. with each of its 66 glomeruli identified with a specific number. The glomeruli in the new atlas are numbered according to the $\mathrm{AL}$ atlases of two other heliothine species (Skiri et al., 2005). For identifying female specific glomeruli comparison with the male AL was necessary, which required a new $H$. virescens male AL atlas, included in this paper. As demonstrated by the three registered AL PNs, the SBAGl is a helpful tool for determining the glomeruli innervated as well as the relative position of the axonal projections in the protocerebrum.

\section{MATERIALS AND METHODS}

Heliothis virescens (Heliothinae; Lepidoptera; Noctuidae) pupae were imported from a laboratory culture (Syngenta, Basel, Switzerland), separated according to sex and placed in different containers in an incubator (Refritherm 6E, Struers) on a phaseshifted LD photoperiod (14:10 hours) at $22^{\circ} \mathrm{C}$. Emerged adults were transferred to new containers and fed ad libitum on a $0.15-\mathrm{M}$ sucrose solution. Experiments were performed on 3-5 days old female and male moths.

\section{STAINING OF THE ANTENNAL LOBE AND PROJECTION NEURONS}

The moths were mounted in plastic tubes and immobilised with dental wax (Kerr Corporation, Romulus, MI, USA). Cephalic scales and mouthparts were removed before decapitation. Brains were dissected in a saline solution (in mM: $150 \mathrm{NaCl}, 3 \mathrm{CaCl}_{2}, 3 \mathrm{KCl}, 25$ $\mathrm{C}_{12} \mathrm{H}_{22} \mathrm{O}_{11}$ and 10 TES buffer, $\mathrm{pH}$ 6.9) and fixed in paraformaldehyde $(4 \%)$ diluted in methanol $(50 \%)$ over night $\left(4^{\circ} \mathrm{C}\right)$. After rinsing in a phosphate buffered saline solution (PBS in mM: $684 \mathrm{NaCl}$, $13 \mathrm{KCl}, 50.7 \mathrm{Na}_{2} \mathrm{HPO}_{4}$ and $5 \mathrm{KH}_{2} \mathrm{PO}_{4}$, pH 7.2; $10 \mathrm{~min}$ ), preparations were dehydrated in an increasing ethanol series $(50,70,90$, 96 and 100\%, 10 min each) degreased in xylol ( $5 \mathrm{~min}$ ), rehydrated in a decreasing ethanol series $(100,96,90,70$ and 50\%, $10 \mathrm{~min}$ each) before washed in PBS (10 $\mathrm{min})$ and preincubated in normal goat serum (NGS; Sigma, St. Louis, MO, USA; 10\%) in PBS at room temperature $(30 \mathrm{~min})$. This was followed by incubation in a monoclonal antibody against the synaptic protein synapsin (SYNORF 1, kindly provided by Prof. E. Buchner, Würzburg, Germany), diluted in PBS (1:10) and NGS (10\%) for $48 \mathrm{~h}\left(4^{\circ} \mathrm{C}\right)$. After rinsing in PBS $(5 \times 20 \mathrm{~min})$ the preparations were incubated for $24 \mathrm{~h}\left(4^{\circ} \mathrm{C}\right)$ with a Cy5-conjungated goat anti-mouse secondary antibody (Jackson Immunoresearch; dilution 1:500 in PBS) before rinsing in PBS $(5 \times 20 \mathrm{~min})$ and dehydrated in increasing ethanol series. Preparations were cleared in methyl salicylate and mounted as whole mounts in double-sided aluminium slides.

For staining of the PNs female moths were restrained and immobilised with wax with the head and antenna protruding. The cuticle between the eyes was removed, exposing the AL and the protocerebrum. Large trachea, intracranial- and antennal muscles were removed to eliminate brain and antennal movements. Neurolemma was perforated with a tungsten hook to facilitate insertion of the microelectrode prior to superfusion with saline solution. Glass microelectrodes were pulled with a Flaming-Brown horizontal puller (P97; Sutter Instruments, Novato, CA, USA), the tips were filled with dye (Micro-Ruby, Invitrogen; 4\%) and backfilled with potassium acetate solution $(0.2 \mathrm{M})$. The microelectrodes had a resistance of 150-400 $\mathrm{M} \Omega$. Neurons were iontophoretically stained by passing a 1-3 nA depolarising current of $2 \mathrm{~Hz}$ with $0.2 \mathrm{~s}$ duration. Complete labelling of the neurons required dye injection for 10-15 min. After current injection, the dye was allowed to diffuse over night at $4^{\circ} \mathrm{C}$ or $3 \mathrm{~h}$ at room temperature. The brains were dissected in saline solution, fixed in paraformaldehyde $(4 \%)$ in PBS and left over night at $4^{\circ} \mathrm{C}$. To intensify the staining of the labelled neurons the brains were incubated in Streptavidin-Cy3 (Jackson Immunoresearch, West Grove, PA, USA; diluted 1:200 in PBS) over night at $4^{\circ} \mathrm{C}$ before rinsed in PBS. Subsequently, the SYNORF1 protocol, as described above, was used on the preparations for background staining. 


\section{VISUALISATION OF THE ANTENNAL LOBE GLOMERULI AND THE PROJECTION NEURONS}

Stained preparations were visualised with a laser scanning confocal microscope (LSM 510 META Zeiss, Jena, Germany). Stained AL preparations were examined using a Zeiss Plan-Neofluar $40 \times 0.75$ NA dry lens objective. The fluorescent dye (Cy5) was exited by a 633-nm line of argon laser and scanned with a resolution of $1024 \times 1024$ pixels in the $x y$-plane and an interslice distance of $2 \mu \mathrm{m}$ (voxel size of $0.75 \mu \mathrm{m} \times 0.75 \mu \mathrm{m} \times 2 \mu \mathrm{m}$ ). Intracellular fillings were examined with a Plan-Neofluar $20 \times / 0.5$ NA dry lens objective. The intracellular dye was excited by a 543-nm Helium Neon laser and filtered through a bandpass filter BP 565-615 IR. Preparations were scanned with a resolution of $1024 \times 1024$ pixels in the $x y$-plane and an interslice distance of $2 \mu \mathrm{m}$. The neurons were scanned in several tiles and manually merged in Amira 4.1. To compensate for the refraction indexes of the mountant and that of the dry lens objective, the $z$-axis dimension was multiplied by a factor of 1.6.

\section{RECONSTRUCTION AND IDENTIFICATION OF THE ANTENNAL LOBE GLOMERULI}

Grey value image stacks acquired from the confocal microscope were elaborately examined section by section and glomeruli were manually labelled using the segmentation editor in Amira 4.1 (Visage Imaging, Fürth, Germany). In this process any group of voxels belonging to a particular glomerulus was given a unique label resulting in a stack of label images corresponding to the underlying confocal images. The label images were used to create $3 \mathrm{D}$ polygonal surface models.

\section{INTEGRATION OF THE ANTENNAL LOBE ATLAS INTO THE STANDARD BRAIN}

The digital SBA of $H$. virescens includes the ALs as models solely constituting the glomerular layer labelled as a single material identity (Kvello et al., 2009). Thus, to register the glomeruli of the AL atlas into the SBA, the separately labelled glomeruli had first to be assigned a single material identity corresponding to the AL model of the SBA. The label image stack of the AL glomeruli was then affineand elastically registered into the corresponding label images of the SBA, i.e. corresponding points in the AL atlas and the AL model of the SBA were transformed into the same coordinates. Subsequently, the glomeruli were relabelled as separate units and given material identity and colour code according to the separate AL atlas.

\section{RECONSTRUCTION AND REGISTRATION OF NEURONS INTO THE NEW STANDARD BRAIN ATLAS WITH GLOMERULI}

Gray value image stacks of stained neurons and innervated brain structures acquired from the confocal microscope were examined and reconstructed in the computer software Amira 3.1, as described by Kvello et al. (2009). Brain structures were reconstructed as label images and neurons by using the skeleton tool (Evers et al., 2004; Schmitt et al., 2004). In general, the registration of neurons into the SBA followed the same procedure as described by Brandt et al. (2005). The label images of the innervated brain structures were affine- and elastically registered to the label images of the corresponding structures in the SBA. Then the resulting transformation parameters for the brain structures were applied to the reconstructed neurons. Since the registration of a neuron into any structure of the SBA requires the identification of the corresponding structure in the preparation, the neurons were first registered into the SBA. The SBAGl was then superposed in order to identify the innervated glomeruli. The identification was checked against the confocal images. The innervated glomeruli as well as a few other landmark glomeruli were subsequently reconstructed in the preparation and registered into the corresponding glomeruli of the SBAGl.

\section{RESULTS}

\section{ATLAS OF ANTENNAL LOBE GLOMERULI}

As expected, the synapsin-specific antibody staining gave a clear labelling of brain structures, particularly the glomeruli of the ALs (Figure 1).

In addition the calyces of the mushroom bodies, the optic lobes and the suboesophageal ganglion were clearly stained. Two of the three AL cell body clusters (Berg et al., 2002), the lateral and the medial, were recognised, but were not further described in this study. The results are based on confocal laser images of the glomeruli of four ALs, one right (Figure 2), and one left from different females and two left from different males.

Figure 3 shows the 3D reconstructions of each glomerulus in the two female and one male preparations.

The ALs of the two female specimens were compared with the female AL model and the underlying confocal images of two other heliothine moth species, Helicoverpa armigera and Helicoverpa assulta (Skiri et al., 2005), to identify corresponding glomeruli that were given the same number and colour. The same procedure was carried out for comparing and numbering the male AL glomeruli. Sex specific glomeruli of the female ALs were identified by comparing the glomeruli between the two sexes. Like in the previous studies, the primary landmarks were the antennal nerve entrance, the central large female glomerulus (cLFG), the male specific MGC, the labial pit organ glomerulus (LPOG), the adjacent large glomerulus medially of the LPOG (mLPOG), and the fibre bundles of the lateral and the medial cell clusters, $\mathrm{LCCl}$ and $\mathrm{MCCl}$, respectively (Figure 3). Surrounding glomeruli of the primary landmarks served as secondary landmarks. This resulted in 4 female specific and 62 ordinary glomeruli in the AL of $H$. virescens females. In males 62 glomeruli corresponded to the ordinary glomeruli in females, whereas 5 glomeruli were male specific, including G63 and the 4 previously described units of the MGC.

\section{FEMALE SPECIFIC GLOMERULI}

The four female specific glomeruli of the $H$. virescens ALs, located at the entrance of the antennal nerve, were identified in both preparations. Centrally at the entrance is the large female specific glomerulus (cLFG) (Figures 2D,E and 3G,H), previously identified in Berg et al. (2002). Two other female specific glomeruli, F1 and F3, were positioned anterior of cLFG and the fourth, F2, posterior of cLFG. Compared with the other heliothine species (Skiri et al., 2005), cLFG has a similar position and size, whereas the position of F1 and F2 differs among the species. F3 is only present in $H$. virescens and $H$. assulta.

\section{ORDINARY GLOMERULI IN FEMALES}

Sixty-six glomeruli were counted in both ALs of the two individuals (Figure 3). Among them, 62 glomeruli corresponded to ordinary glomeruli in the AL of $H$. virescens males and of the two other heliothine species, $H$. armigera and $H$. assulta. For instance, easily 

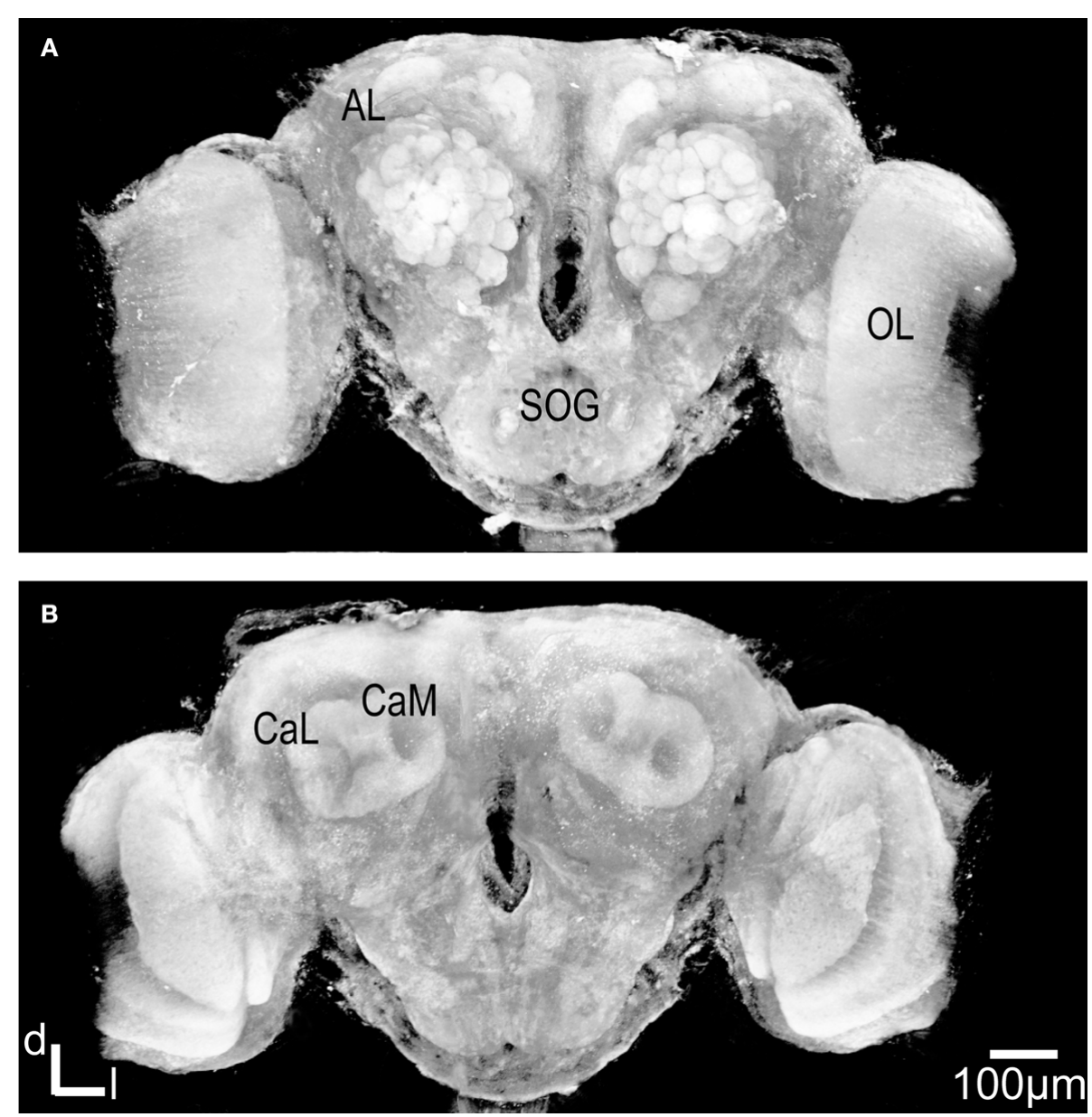

FIGURE 1 |Three dimensional visualisation of the confocal image stack of the $\boldsymbol{H}$. virescens female moth brain. (A)The brain in a frontal view exposing the two antennal lobes (AL) with the numerous glomeruli. (B) The brain in posterior view showing the calyces of the mushroom bodies. OL, optic lobes; SOG, suboesophageal ganglion; $\mathrm{CaL}$, lateral calyx; CaM, medial calyx.

recognised in all ALs are the two primary landmarks, the large LPOG and mLPOG, which are given the numbers G38 and G39, respectively, according to Skiri et al. (2005). Posterior of G39 is G53 with five dorso-medially located glomeruli, G58-G62 (Figures 3J,K). At the entrance of the antennal nerve, posterior of CLFG, are four recognised glomeruli G51, G52, G56 and G57. Three other glomeruli, G49, G50 and G54, are recognised most dorsal in the AL, and G37, G36 and G35 dorso-medially of the LCCl fibre bundle (Figures 3G,H). On the basis of these recognised and identified primary and secondary landmarks, the other 42 glomeruli were identified and given numbers according to the other heliothine atlases (Skiri et al., 2005). This is exemplified in Figure 3, showing the clockwise numbering of G1-G23 (Figures 3A,B), G24-G34 (Figures 3D,E), G35-G48 (Figures 3G,H) and G49-G63 (Figures 3J,K), appearing in sections from anterior to posterior. In this way, all 62 glomeruli in both $H$. virescens female preparations were found to correspond with the ordinary glomeruli in the atlases of the other heliothine species.

\section{COMPARISON OF NUMBERS AND POSITIONS OF GLOMERULI}

Whereas the number of the glomeruli was constant in the ALs of the examined specimens, some variations were found regarding positions and sizes of a few glomeruli. For instance, the position of G1 and G2 is shifted anterior-posterior in the two preparations and the size of G2 and G5 is marked larger in one preparation than in the other (Figures 3A,B). Other variations between the two $H$. virescens preparations are the relative positions of G25, G24 and F1 and between G28 and G38. Comparison with the previous $H$. virescens atlas, the differences concern the total number of glomeruli identified as well as the way of numbering the glomeruli. Concerning the female specific glomeruli, only two (cLFG and medially of it the mLFG) were identified by Berg et al. (2002). The eight ordinary glomeruli G11-G13, G25, G34 and G45-G47 in the present atlas were counted as four units in the previous atlas. Oppositely, G62 and G22 in the present atlas seem to be counted as four in the previous atlas. The corresponding numbers of the two atlases are presented in Table 1.

\section{MALE SPECIFIC AND ORDINARY GLOMERULI}

Like in females, the MGC is located at the entrance of the antennal nerve. As previously described it consists of the cumulus, the dorso-medial and the two ventral glomeruli (Figures 3C,F), and differs from the MGC of the two other heliothine species having only three glomeruli (Berg et al., 2002; Skiri et al., 2005). The MGC served as an additional primary landmark in the identification of the ordinary glomeruli. Using the same way of identification as in 

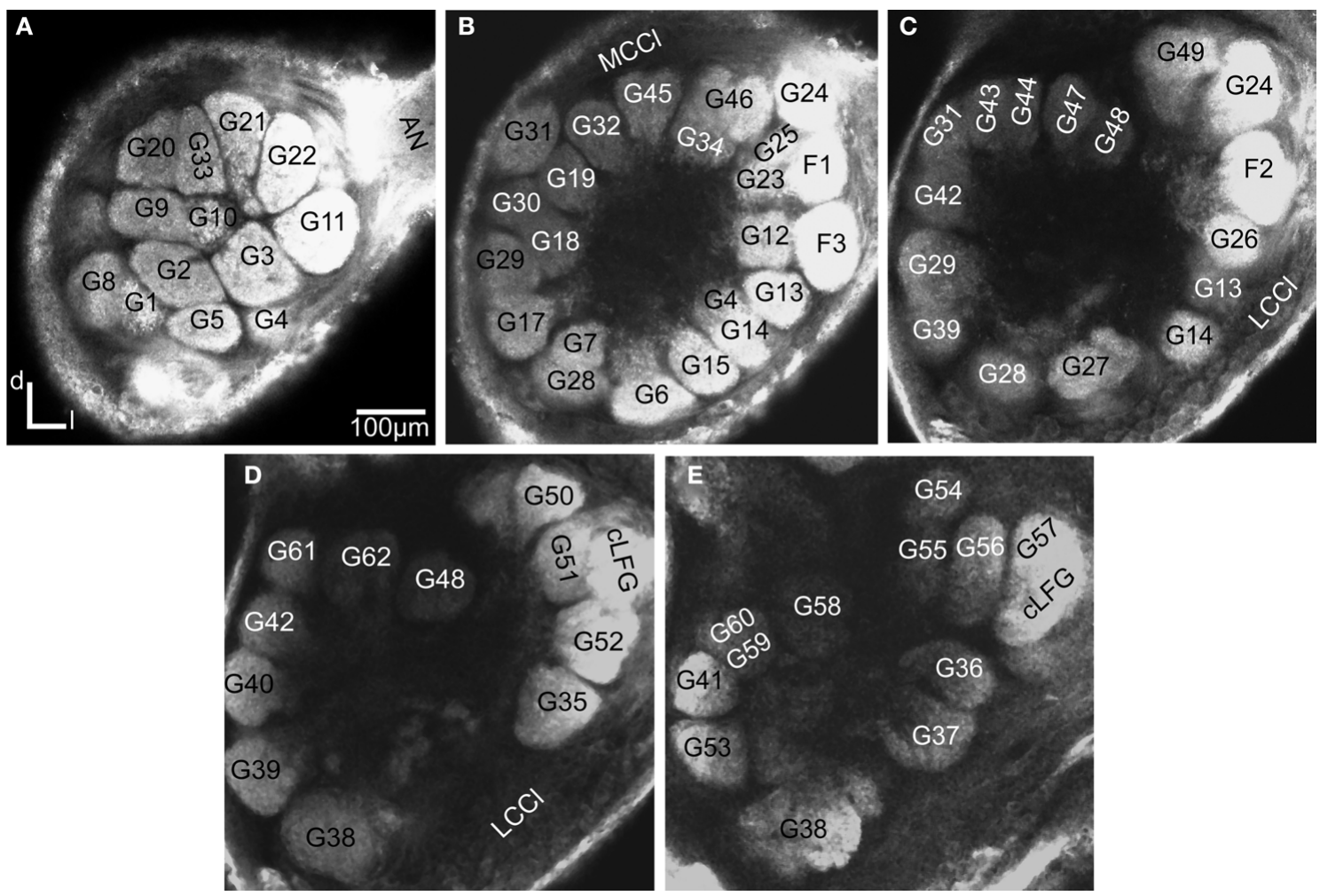

FIGURE 2 | Confocal images at different depths of the right $\boldsymbol{H}$. virescens female antennal lobe, from anterior towards posterior at the following depths: (A) $64 \mu \mathrm{m}$, (B) $105 \mu \mathrm{m}$, (C) $144 \mu \mathrm{m}$, (D) $179 \mu \mathrm{m}$, (E) $216 \mu \mathrm{m}$. Except for G16 all glomeruli are shown. The AL is inverted.

the female AL, 63 ordinary glomeruli were identified in the male AL, of which G1-G62 showed correspondence with the female ordinary glomeruli and G63 being male specific.

\section{INTEGRATION OF THE ANTENNAL LOBE GLOMERULI INTO THE STANDARD BRAIN ATLAS}

Registration of the AL glomeruli into the SBA resulted in the new female $H$. virescens SBA with 66 identified glomeruli (SBAGl) (Figure 4A).

The two reconstructed female ALs were independently integrated into the SBAGl. After transforming the glomeruli into the SBA, the shape and size of the glomeruli in SBAGl matched the glomerular layer in the SBA. The relative position of the glomeruli was maintained in the transformation process making the glomeruli easily recognisable (Figures 4B,C). Thus, they were relabelled and given numbers and colours corresponding to the separate AL atlas. With this new and more detailed anatomical atlas of the $H$. virescens brain, we next wanted to study the specific glomerular innervation of three $\mathrm{AL}$ PNs and their projection patterns in the protocerebrum.

\section{INTEGRATION OF ANTENNAL LOBE PROJECTION NEURONS INTO THE SBAGI}

The present results include three stained AL PNs registered into the SBAGl (Figures 5-7).

These neurons with axons following the IACT are termed PI neurons (Homberg et al., 1988; Rø et al., 2007). The initial registration of each of them into the SBA by transforming the AL as a single material identity revealed the glomerular area of the dendritic innervations in the AL as well as the axonal pathway and branching pattern in the calyces and the lateral protocerebrum. After superposing the glomeruli of the SBAGl, the innervated glomeruli clearly appeared. As exemplified by the neuron shown in Figures 5A, 6, and 7, the innervations were identified in three glomeruli, G35, G36 and G37. The dendrite differentially innervated each of the three glomeruli; G37 stronger than G35 and only one branch in G36. The axon following the IACT, passed adjacent and posteriorlaterally to the central body (Figures 6A,B). Upon reaching the calyces of the ipsilateral mushroom body, the axon gave off five branches innervating the medial and lateral calyces before turning anteriorlaterally into the lateral protocerebrum, showing a star-like projection pattern. Most branches turned dorsally and only one ventrolaterally into the lateral horn (Figures 6A-C), defined as the protrusion from the lateral protocerebrum according to Kvello et al. (2009). The soma was located in the lateral cell cluster close to the innervated glomerulus, G37. A second $\mathrm{PN}$ with cell soma in the lateral cluster was registered by the same procedure into the SBAGl (Figures 5B and 7). This neuron innervated a single glomerulus identified as G14, located close to its cell body. The axon followed quite closely the axon of the G37 neuron, and also gave off five branches to the calyces before turning anteriorlaterally and extending into the lateral protocerebrum. The same pattern of star-like projections appeared with most branches turning dorsally and one ventrolaterally towards the lateral horn. The third neuron registered into the SBAGl, showed innervation of a single glomerulus identified as G11, located in the anterior part of the AL (Figures 5C and 7). The soma was in the anterior 


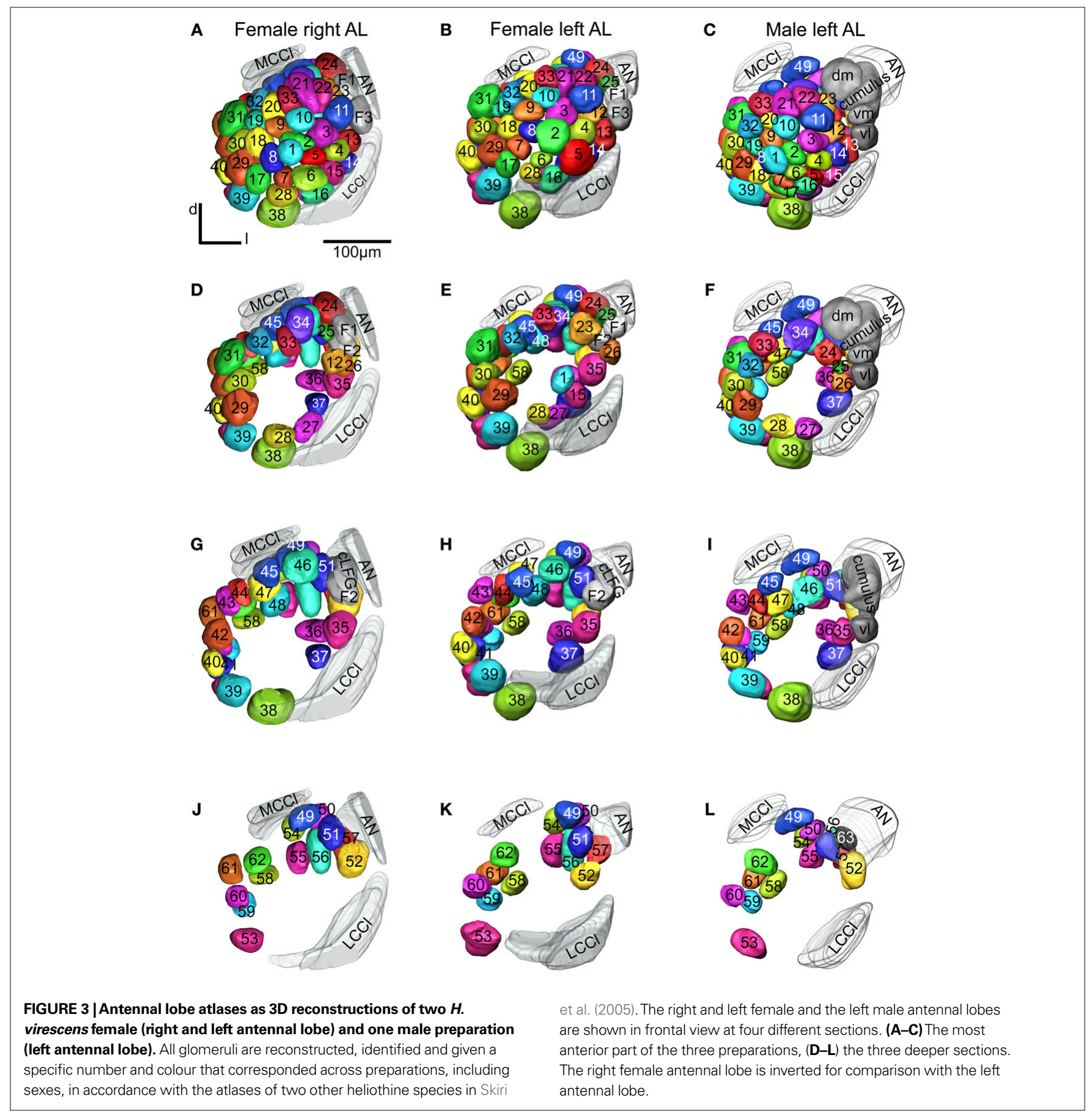

cluster, close to the innervated glomerulus. The innervation was extensive throughout the whole glomerulus (Figure 5C). The axon followed the IACT sending four branches into the medial and lateral calyces before turning anteriorlaterally towards the lateral protocerebrum, where it projected in the typical star-like pattern with most branches extending dorsally and one ventrolaterally into the lateral horn.

Comparison of the three neurons in the SBAGl shows their relative position from the different glomerular innervation to their projections in the calyces and the lateral protocerebrum (Figure 7). The two neurons innervating the more posteriorventrally located
G35, G36, G37 and G14, respectively, with soma in the lateral cell cluster have axons running in a ventral pathway into the protocerebrum. The axon of the neuron innervating the dorsoanterior G11 with soma in the anterior cluster runs more dorsally in the $\mathrm{AL}$ and protocerebrum before joining the other axons in the IACT anteriorly and close to the central body. The axonal projections of the three neurons in the calyces intermingle, whereas in the lateral protocerebrum the axonal projections appears organised in a dorsoventral axis with partly overlap. The projections of the G14 neuron are dorsally to those of the G11 neurons, which are again dorsally to those of the G37 neuron. 
Table 1 | Glomeruli of $\boldsymbol{H}$. virescens antennal lobe atlases with corresponding numbers in the new and the previous atlas.

\begin{tabular}{|c|c|c|c|c|c|}
\hline \multirow{3}{*}{$\begin{array}{l}\text { New atlas } \\
F \text { and } M\end{array}$} & & & \multicolumn{3}{|l|}{ New atlas } \\
\hline & \multicolumn{2}{|c|}{ Previous atlas } & \multirow[t]{2}{*}{$F$ and $M$} & \multicolumn{2}{|c|}{ Previous atlas } \\
\hline & $\mathbf{F}$ & M & & $\mathbf{F}$ & M \\
\hline G1 & $\mathrm{G} 1$ & G8 & G36 & G45 & G57 \\
\hline G2 & G7 & G3 & G37 & G37 & $\mathrm{G} 41$ \\
\hline G3 & G57 & G6 & G38 & G19 & G39 \\
\hline G4 & G8 & $\mathrm{G} 2$ & G39 & $\mathrm{G} 21$ & G35 \\
\hline G5 & $\mathrm{G} 2$ & G7 & $\mathrm{G} 40$ & $\mathrm{G} 22$ & G42 \\
\hline G6 & G6 & $\mathrm{G} 17$ & G41 & G43 & $\mathrm{G} 48$ \\
\hline G7 & G3 & $\mathrm{G} 23$ & $\mathrm{G} 42$ & G42 & $\mathrm{G} 47$ \\
\hline G8 & G4 & $\mathrm{G} 1$ & $\mathrm{G} 43$ & G24 & G38 \\
\hline \multirow[t]{2}{*}{ G9 } & G5 & $\mathrm{G} 12$ & G44 & $\mathrm{G} 23$ & $\mathrm{G} 40$ \\
\hline & & $\mathrm{G} 18$ & G45 & $\mathrm{G}^{1} 3^{1}$ & G33 \\
\hline $\mathrm{G} 10$ & G11 & G5 & G46 & $\mathrm{G}^{\prime} 2^{1}$ & $\mathrm{G} 24^{1}$ \\
\hline G11 & G58 & G4 & G47 & $\mathrm{G}^{\prime} 3^{1}$ & G45 \\
\hline G12 & $\mathrm{G}^{1} 6^{1}$ & $\mathrm{G} 22$ & $\mathrm{G} 48$ & $\mathrm{G} 26$ & G53 \\
\hline G13 & $\mathrm{G}^{1} 6^{1}$ & $\mathrm{G} 25$ & G49 & G54 & G54' \\
\hline G14 & G30 & G10 & G50 & G39 & G55 \\
\hline G15 & $\mathrm{G} 18$ & G19 & G51 & G41 & 3 \\
\hline G16 & G9 & $\mathrm{G} 21^{1}$ & G52 & G38 & G58 \\
\hline G17 & $\mathrm{G} 20$ & G16 & & & G59 \\
\hline G18 & $\mathrm{G} 12$ & G15 & G53 & G44 & G36 \\
\hline G19 & G27 & G26 & & & G49 \\
\hline G20 & G15 & $\mathrm{G} 27$ & G54 & G53 & G54 ${ }^{1}$ \\
\hline G21 & G17 & $\mathrm{G} 13$ & G55 & G52 & 3 \\
\hline \multirow[t]{2}{*}{$\mathrm{G} 22$} & $\mathrm{G} 32^{2}$ & G9 & G56 & G51 & G56 \\
\hline & G60 & G62 & G57 & G40 & G60 \\
\hline G23 & G59 & $\mathrm{G} 11$ & & & G61 \\
\hline G24 & $\mathrm{mLFG}$ & 3 & G58 & G48 & 3 \\
\hline G25 & G58' & G14 & G59 & G50 & G51 \\
\hline G26 & G35 & G43 & G60 & G49 & G46 \\
\hline \multirow[t]{2}{*}{ G27 } & G28 & G32 & G61 & G47 & G50 \\
\hline & & $\mathrm{G} 21^{2}$ & G62 & G55 & G52 \\
\hline G28 & G10 & G31 & & G56 & \\
\hline \multirow[t]{2}{*}{ G29 } & G14 & $\mathrm{G} 28$ & G63 & & Cumulus ${ }^{2}$ \\
\hline & & G34 & Cumulus & & Cumulus $^{1}$ \\
\hline G30 & $\mathrm{G} 13$ & G30 & $\mathrm{dm}$ & & $\mathrm{dm}$ \\
\hline G31 & $\mathrm{G} 25$ & G29 & $\mathrm{vm}$ & & $\mathrm{vm}$ \\
\hline G32 & G29 & G37 ${ }^{1}$ & CLFG & cLFG & \\
\hline \multirow[t]{2}{*}{ G33 } & G16 & $\mathrm{G} 20$ & F1 & G31 & \\
\hline & & $\mathrm{G} 37^{2}$ & F2 & G34 & \\
\hline G34 & G32 ${ }^{1}$ & $\mathrm{G} 24^{1}$ & F3 & 3 & \\
\hline G35 & G46 & G44 & & & \\
\hline
\end{tabular}

F, female; $M$, male.

${ }^{1}$ Two glomeruli counted as one.

${ }^{2}$ Includes a part of adjacent glomerulus.

${ }^{3}$ Glomeruli not found.

\section{DISCUSSION}

ANTENNAL LOBE GLOMERULI INTEGRATED INTO THE STANDARD BRAIN ATLAS

How glomerular activity in the primary olfactory centres represents odour information and how this topographic organisation is further reflected in higher olfactory areas, are central questions in studies on the functional organisation of vertebrate as well as insect olfactory systems. A major challenge is to map in higher olfactory brain neuropils the target areas of the primary olfactory centre's output neurons, according to the glomerular input; in Drosophila made possible by the use of molecular labelling of PNs (Wong et al., 2002; Tanaka et al., 2004; Jefferis et al., 2007). In the honeybee and the moth $H$. virescens, whole brain standard atlases have been demonstrated as helpful tools in determining the projections in the calyces and the lateral protocerebrum of AL PNs (Brandt et al., 2005; Kvello et al., 2009). Particularly in the lateral protocerebrum with no visible substructures, integrated PNs from different preparations give important information about their relative positions. However, because of the low resolution confocal scans used for creating the whole brain atlases, separate atlases with higher resolution are better suited for determining the PNs input and output regions, respectively. By integration of the AL glomeruli into the $H$. virescens $\mathrm{SBA}$ as shown in the present study, the PN input and output regions were standardised in this common framework, SBAGl. This integration process was facilitated by the fact that the $\mathrm{AL}$ of this atlas included the glomerular layer only, excluding tracts and cell clusters; different from the four other atlases. Therefore, the AL atlas glomeruli could be directly registered into the SBA, after being assigned a single material identity. Since the relative position of the glomeruli was maintained in the transformation process, all 66 glomeruli could easily be recognised, relabelled and numbered according to the AL atlas (Figure 4). The anatomically more detailed SBAGl provides a stronger basis for studying the specific innervations in the AL as well as the connections to higher brain areas, like the calyces and the lateral protocerebrum.

\section{ANTENNAL LOBE PROJECTION NEURONS INTEGRATED INTO THE SBAGI}

In principle, the integration of reconstructed $\mathrm{AL}$ neurons into the SBAGl is a two-step process as described for the neurons presented in Figures 5-7. The first step constitutes a registration into the SBA which guides the localisation of the dendritic innervation to a particular area of the AL. Then, superposing the SBAGl reveals the innervated glomeruli. This procedure used for the well stained preparations in the present study allowed verification of the glomerular innervation in confocal images. This means that the procedure can be used even for preparations where glomeruli may not be well distinguished, as long as the glomerular borderline is clearly detectable. The well stained preparations in the present study made reconstruction of the innervated and landmark glomeruli possible. The registration of these glomeruli into the SBAGl resulted in a precise position of the dendritic innervation within the glomeruli. Thus, the SBAGl is an extended and more elaborate tool that together with the confocal images expands the possibility for making accurate judgments of dendritic arborisation and identification of the innervated glomeruli.

In addition to the high resolution model of the AL facilitating the identification of glomerular innervation, the SBAGl also provides the frame for visualising the relative position of whole neurons in the brain. As shown in Figures $\mathbf{6}$ and 7, the details on the neuronal pathways are for instance visualised by the different axonal trajectories in the AL before joining in the IACT. The uniglomerular innervation and extensive branching throughout the glomerulus as 
в
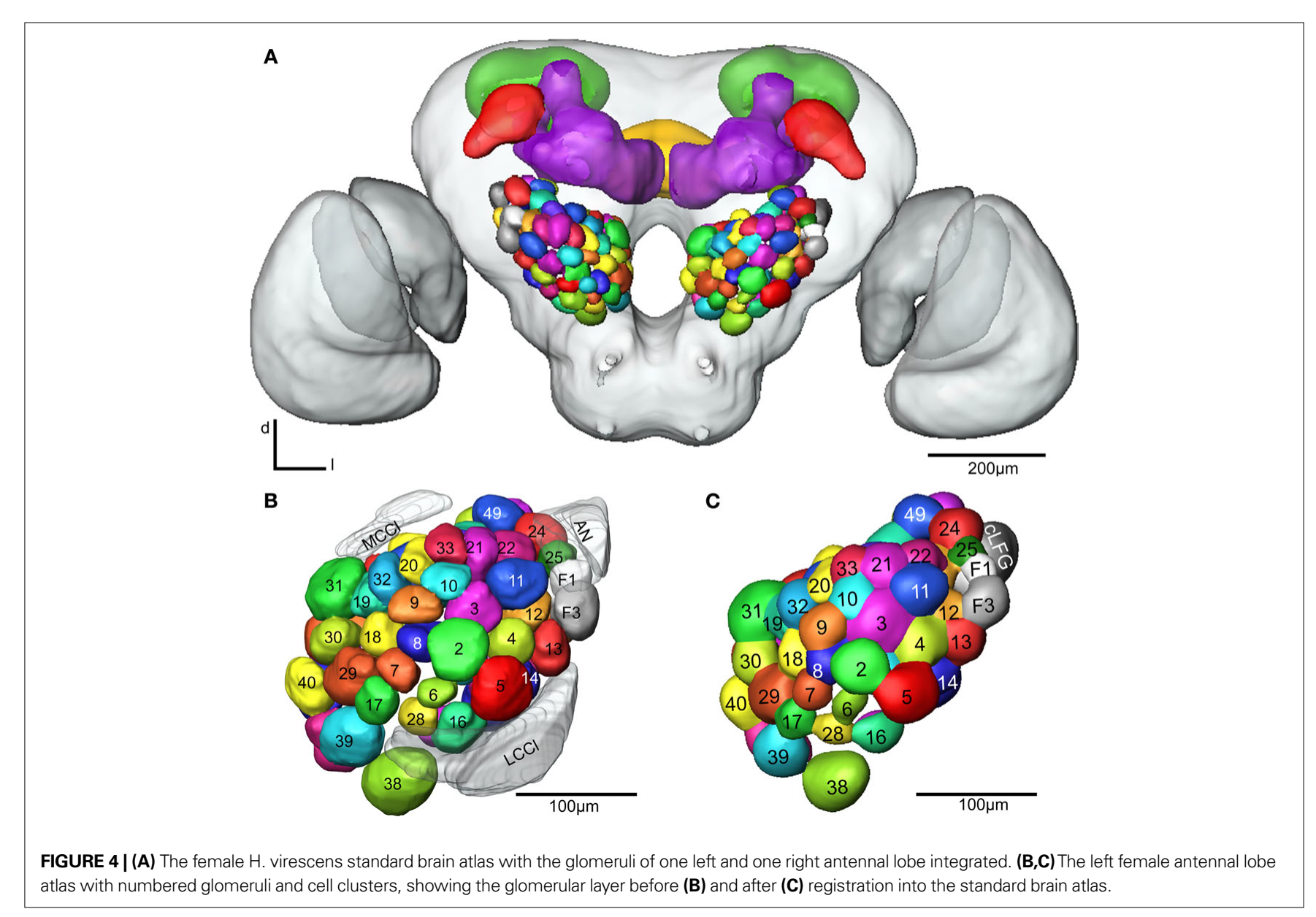

A) female $\mathrm{H}$. virescens standard brain atlas with the glomeruli of one left and one right antennal lobe integrated. (B,C) The left female antennal lobe

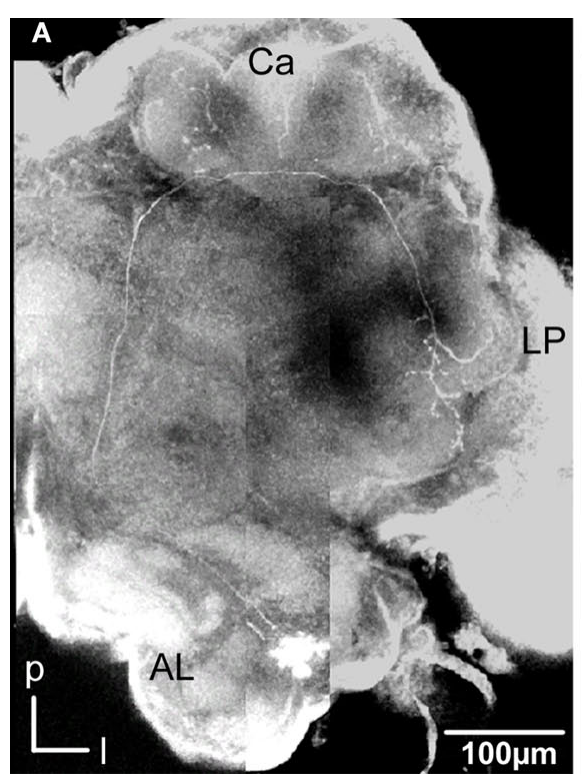

FIGURE 5 | Stacks of confocal images of three preparations each with one stained projection neuron having axon in the inner antennocerebral tract. (A) Dorsal view: This neuron innervated three glomeruli (G35, G36 and G37) and projected in the calyces with five branches (three visible) before turning anteriorlaterally and projecting in lateral protocerebrum. (B) Dorsal view: This neuron
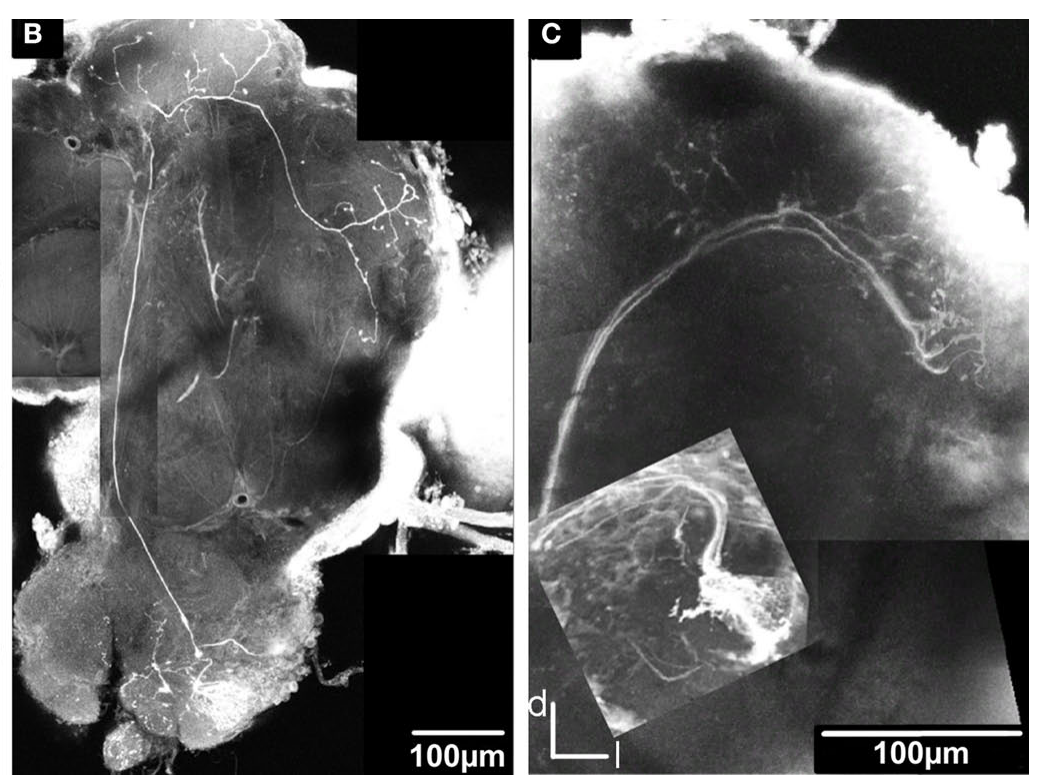

innervated G14 and projected in calyces with five branches before turning anteriorlaterally into the lateral protocerebrum. The starlike projection with dorsal branches as well as a single ventral branch into the lateral horn is visible. (C) Frontal view:

This neuron (co stained with a second neuron, from Kvello et al., 2009) innervated G11. The projection in the calyces and the lateral protocerebrum is shown. 

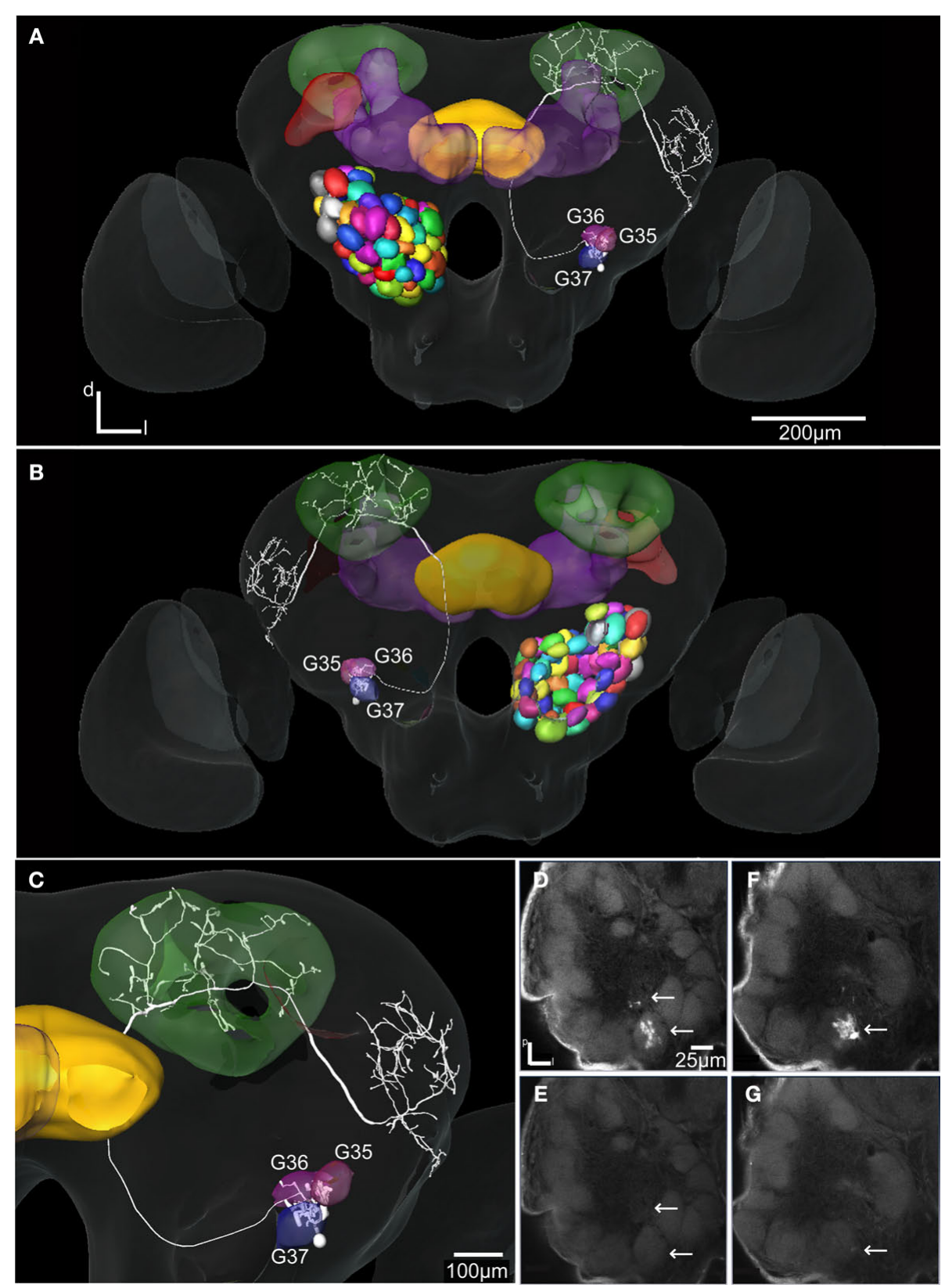

FIGURE 6 |The $\boldsymbol{H}$. virescens standard brain atlas with one integrated antennal lobe projection neuron (the same as in Figure 5A). (A) Frontal view. (B) Posterior view. (C) Magnified frontal view showing the innervated glomeruli and projection pattern in the medial and lateral calyces and in the lateral protocerebrum. (D-G) Confocal images showing the triple glomerular innervation in two different sections scanned with two channels. (D) Micro-ruby staining showing the innervation of glomeruli G37 and G36. (E) Synapsin staining visualising the glomeruli of the same section. (F) Micro-ruby staining showing the innervation of glomerulus G35. (G) Synapsin staining visualising the glomeruli of the same section. Arrows indicate innervated glomeruli. shown for the G11 and G14 neurons are typical features for IACT PNs (category PIa in Homberg et al., 1988; Rø et al., 2007). These neurons found in most insect species belong to a conserved group of PNs (Schachtner et al., 2005). IACT neurons innervating a few adjacent glomeruli have also been identified in $H$. virescens (category PIc in Rø et al., 2007), similar to the G37 neuron with dendritic arborisations in the two adjacent glomeruli, G35 and G36. The innervation pattern in protocerebrum, shown for the three neurons in Figure 7, is typical for IACT neurons. As previously described, they send three to five branches into the calyces and extend the axon into the lateral protocerebrum ending in a star-like projection, where most branches project dorsally and one branch ventrolaterally towards or into the lateral horn, like the IACT neurons in the present study. By using the SBAGl combined with registration algorithms for integrating the neurons we have here found that the three IACT neurons innervate distinct but overlapping areas 

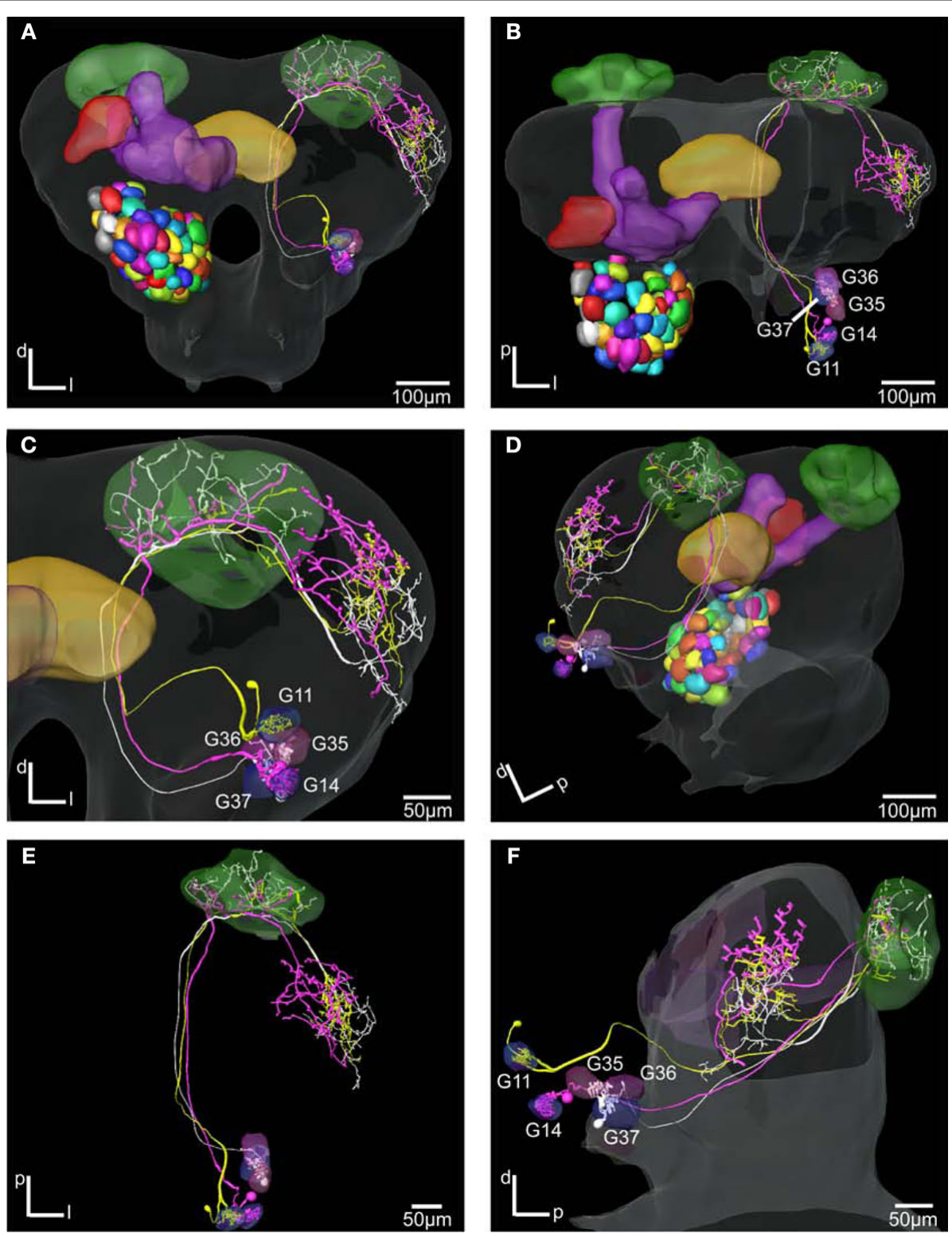

FIGURE 7 |The $\boldsymbol{H}$. virescens standard brain atlas with three antennal lobe projection neurons integrated. (A,C) Frontal view. (B,E) Dorsal view. (D) Posterior lateral view. (F) Lateral view. The relative positions of the innervated glomeruli and projections as well as the axonal pathways are shown in the different views. The projections pattern in the lateral protocerebrum in different but overlapping areas along a dorsoventral axis appears particularly in (C) and (F). The dorsal axonal pathway in the antennal lobe of the G11 neuron before joining the other axons in the inner antennocerebral tract is clearly seen in (A) and (B). along a dorsoventral axis in the lateral protocerebrum (Figure 7). Whether this organisation is consistent with the actual organisation or due to methodological limitations remains to be verified. In contrast, the two PNs innervating the same glomerulus showed intermingled projections in the same area (Kvello et al., 2009). A similar principle for the organisation of $\mathrm{PN}$ projections is found in the lateral horn of Drosophila, where molecularly labelled neurons innervating the same glomerulus exhibited similar axonal topography, whereas neurons from different glomeruli displayed different projection patterns (Wong et al., 2002). A further division of the lateral horn in Drosophila into sub-regions according to different PN projection clusters is described by Jefferis et al. (2007). How the projection pattern of $\mathrm{PN}$ populations in $H$. virescens are organised in the lateral protocerebrum according to the innervated glomeruli as well to the different tracts, are interesting questions to be resolved when more PNs have been integrated into the SBAGl.

\section{COMPARISON OF ANTENNAL LOBE ATLASES BETWEEN SEXES AND SPECIES}

In the present study we provided a new atlas of the AL of $H$. virescens females, based on the numbering system of two other heliothine moth species (Skiri et al., 2005). In general, the challenge in this kind of work is to detect the borders between the glomeruli. The difference from the previous $H$. virescens atlas in 
respect to the number of glomeruli included seems to be due to the lack of detectable borderlines between pairs of glomeruli in the lower resolution confocal images of the previous atlas (Berg et al., 2002). The glomeruli in the present $H$. virescens atlas showed a striking correspondence with the glomeruli of the atlases of the two other heliothine species (Skiri et al., 2005), which is the basis for the identification of the glomeruli with corresponding numbers. Thus, the new $H$. virescens atlas is more reliable for identifying the glomeruli innervated by a neuron, as well as suited for comparing the results between heliothine species. For instance, a challenging question is whether corresponding glomeruli in the three species also receive and process information about the same odorants or the odorant specificity has changed through evolution. An interesting example on possibly conserved specificity is for the large LPOG or G38, present in the typical position in the AL of lepidopteran species, and in Manduca sexta shown to be involved in mediating information about $\mathrm{CO}_{2}$ (Gurenstein et al., 2004). The male AL atlas included in this study provides a basis for detecting similarities and differences with the female olfactory system both concerning morphology and physiology. Interestingly, except for one additional glomerulus, G63, in the male AL, the numerous ordinary glomeruli corresponded well between the two sexes as well as between the species. Because of this correspondence within and between sexes and species (all together 12 individual ALs), we

\section{REFERENCES}

Anton, S., and Hansson, B. S. (1999). Physiological mismatching between neurons innervating olfactory glomeruli in a moth. Proc. R. Soc. Lond., B, Biol. Sci. 266, 1813-1820.

Anton, S., and Homberg, U. (1999). Antennal lobe structure. In Insect Olfaction, B. S. Hansson, ed. (Berlin, Springer), pp. 97-124.

Axel, R. (1995). The molecular logic of smell. Sci. Am. 273, 154-159.

Berg, B. G., Almaas, T. J., Bjaalie, J. G., and Mustaparta, H. (1998). The macroglomerular complex of the antennal lobe in the tobacco budworm moth Heliothis virescens: specified subdivision in four compartments according to information about biologically significant compounds. J. Comp. Physiol. A 183, 669-682.

Berg, B. G., Galizia, C. G., Brandt, R., and Mustaparta, H. (2002). Digital atlases of the antennal lobe in two species of tobacco budworm moths, the oriental Helicoverpa assulta (male) and the American Heliothis virescens (male and female). J. Comp. Neurol. 446, 123-134.

Brandt, R., Rohlfing, T., Rybak, J., Krofczik, S., Maye, A., Westerhoff, M., Hege, H. C., and Menzel, R. (2005). Treedimensional average-shape atlas of the honeybee brain and its applications. J. Comp. Neurol. 492, 1-19.

Buck, L. B. (2000). The molecular architecture of odor and pheromone sensing in mammals. Cell 100, 611-618.

find that the present results are reliable as concerns numbers and relative positions of the glomeruli. In the present study we have integrated the AL glomeruli into the SBA of $H$. virescens and shown its suitability for integrating and visualising AL neurons. So far, we have only registered PNs of the IACT, showing their relative positions. The intention is to integrate physiologically characterised PNs of all tracts for relating glomerular innervation in the AL to axonal projections in the protocerebrum. Functional similarities and differences among the PNs may in this way be related to specific input, output or ACTs, the latter associated with functionally different PNs in the honeybee (Müller et al., 2002). In a previous study, we have compared the spatial relationship between a few olfactory and gustatory neurons showing adjacent projection areas in the lateral protocerebrum (Kvello et al., 2009). Thus, integration of more physiologically characterised chemosensory neurons may visualise the neuronal network underlying chemosensory coding in this moth species.

\section{ACKNOWLEDGMENTS}

The project was financed by the Royal Norwegian Society of Sciences and Letters. We also acknowledge Dr. Hanne Skiri for help with making the AL atlas, Prof. Erich Buchner (Universität Würzburg, Germany) for providing antibodies, and the Insect Rearing Team of Syngenta (Basel, Switzerland) for providing insect materials.

Flanagan, D., and Mercer, A. R. (1989). An atlas and 3-D reconstruction of the antennal lobes in the worker honey bee, Apis mellifera L. (Hymenoptera: Apidae). Int. J. Insect. Morphol. Embryol. 18, 145-159.

Galizia,C.G., McIlwrath, S.L., and Menzel, R. (1999). A digital three-dimensional atlas of the honeybee antennal lobe based on optical sections acquired by confocal microscopy. Cell Tissue Res. 295, 383-394.

Galizia, C. G., and Menzel, R. (2000). Probing the olfactory code. Nat. Neurosci. 3, 853-854.

Galizia, C. G., Sachse, S., and Mustaparta, H. (2000). Calcium responses to pheromones and plant odours in the antennal lobe of the male and female moth Heliothis virescens. J. Comp. Physiol. A 186, 1049-1063.

Greiner, B., Gadenne, C., and Anton, S. (2004). Three-dimensional antennal lobe atlas of the male moth, Agrotis ipsilon: a tool to study structurefunction correlation. J. Comp. Neurol. 475, 202-210.

Gurenstein. P. G., Christensen. T. A., and Hildebrand. J. G. (2004). Sensory processing of ambient $\mathrm{CO}_{2}$ information in the brain of the moth Manduca sexta. J. Comp. Physiol. A. 190, 707-725.

Heisenberg, M. (2003). Mushroom body memoir: from maps to models. Nat. Rev. Neurosci. 4, 266-275.

Hildebrand, J. G., and Shepherd, G. M. (1997). Mechanisms of olfactory discrimination: converging evidence for common principles across phyla. Annu. Rev. Neurosci. 20, 595-631.

Homberg, U., Montague, R. A., and Hildebrand, J. G. (1988). Anatomy of antenno-cerebral pathways in the brain of the sphinx moth Manduca sexta. Cell Tissue Res. 254, 255-281.

Huetteroth, W., and Schachtner, J. (2005). Standard three-dimensional glomeruli of the Manduca sexta antennal lobe: a tool to study both developmental and adult neuronal plasticity. Cell Tissue Res. 319, 513-524.

Iyengar, B. G., Chou, C. J., Sharma, A., and Atwood, H.L. (2006). Modular neuropile organization in the Drosophila larval brain facilitates identification and mapping of central neurons. J. Comp. Neurol. 499, 583-602.

Jefferis, G. S. X. E., Potter, C. J., Chan. A. I., Marin,E.C., Rohlfing, T., Maurer,C. R., and Luo, L. Q. (2007). Comprehensive maps of Drosophila higher olfactory centers: spatially segregated fruit and pheromone representation. Cell 128, 1187-1203.

Kanzaki, R., Soo, S., Seki, Y., and Wada, S. (2003). Projections to higher olfactory centers from subdivisions of the antennal lobe macroglomerular complex of the male silkmoth. Chem. Senses 28, 113-130.

Kazawa, T., Namiki, S., Fukushima, R., Terada, M., Soo, K., and Kanzaki, R. (2009). Constancy and variability of glomerular organization in the antennal lobe of the silkmoth. Cell Tissue Res. 336, 119-136. 
Kloppenburg, P., and Mercer,A. R. (2008). Serotonin modulation of moth central olfactory neurons. Annu. Rev. Entomol. 53, 179-190.

Kurylas, A. E., Rohlfing, T., Krofczik, S., Jenett, A., and Homberg, U. (2008). Standardized atlas of the brain of the desert locust, Schistocerca gregaria. Cell Tissue Res. 33, 125-145.

Kvello, P., Løfaldli, B. B., Rybak, J., Menzel, R., and Mustaparta,H. (2009). Digital, three-dimensional average shaped atlas of the Heliothis virescens brain with integrated gustatory and olfactory neurons. Front. Syst. Neurosci. 3:14. doi: 10.3389/neuro.06.014.2009.

Laissue, P. P., Reiter, C., Hiesinger, P. R., Halter, S., Fischbach, K. F., and Stocker, R. F. (1999). Three-dimensional reconstruction of the antennal lobe in Drosophila melanogaster. J. Comp. Neurol. 405, 543-552.

Laurent, G., Wehr, M., and Davidowitz, H. (1996). Temporal representations of odors in an olfactory network. J. Neurosci. 16, 3837-3847.

Lledo, P.-M., Gheusi, G., and Vincent, J.-D. (2005). Information processing in the mammalian olfactory system. Physiol. Rev. 85, 281-317.

Masante-Roca, I., Gadenne, C., and Anton, S. (2005). Three-dimensional antennal lobe atlas of male and female moths, Lobesia botrana (Lepidoptera: Tortricidae) and glomerular representation of plant volatiles in females. J. Exp. Biol. 208, 1147-1159.

Menzel, R. (2001). Searching for the memory trace in a mini-brain, the honeybee. Learn. Mem. 8, 53-62.

Mombaerts, P. (2001). How smell develops. Nat. Neurosci. 4, 1192-1198.

Müller, D., Abel, R., Brandt, R., Zöckler, M., and Menzel, R. (2002). Differential parallel processing of olfactory information in the honeybee, Apis mellifera L. J. Comp. Physiol. A. $188,359-370$.

Mustaparta, H. (2002). Encoding of plant odour information in insects: peripheral and central mechanisms. Entomol. Exp. Appl. 104, 1-13.
Mustaparta, H., and Stranden, M. (2005). Olfaction and learning in moths and weevils living on angiosperm and gymnosperm hosts. Recent Adv. Phytochem. 39, 269-292.

Rein, K., Zöckler, M., Mader, M. T., Grübel, C., and Heisenberg, M. (2002). The Drosophila standard brain. Curr. Biol. 12, 227-231.

Reischig, T., and Stengl, M. (2002). Optic lobe commissures in a three-dimensional brain model of the cockroach Leucophaea maderae: a search for the circadian coupling pathways. J. Comp. Neurol. 443, 388-400.

Rø, H., Müller, D., and Mustaparta, H. (2007). Anatomical organization of antennal lobe projection neurons in the moth Heliothis virescens. J. Comp. Neurol. 500, 658-675.

Rospars, J. P., and Chambille, I. (1981). Deutocerebrum of the cockroach Blaberus craniifer burm. Quantitative study and automated identification of the glomeruli. J. Neurobiol. 12, 221-247.

Rospars, J. P., and Hildebrand, J. G. (2000). Sexually dimorphic and isomorphic glomeruli in the antennal lobes of the sphinx moth Manduca sexta. Chem. Senses 25, 119-129.

Røstelien, T., Stranden, M., Borg-Karlson, A.-K., and Mustaparta, H. (2005). Olfactory receptor neurones in two heliothine moth species responding selectively to aliphatic green leaf volatiles, aromatics, monoterpenes and sesquiterpenes of plant origin. Chem. Senses 30, 443-461.

Sadek, M. M., Hansson, B. S., Rospars, J. P., and Anton, S. (2002). Glomerular representation of plant volatiles and sex pheromone components in the antennal lobe of the female Spodoptera littoralis. J. Exp. Biology. 205, 1363-1376.

Schachtner, J., Schmidt, M., and Homberg, U. (2005). Organization and evolutionary trends of primary olfactory brain centers in Tetraconata (Crustacea + Hexapoda). Arthropod Struct. Dev. 34, 257-299.
Schmitt, S., Evers, J. F., Duch, C., Scholz, M., and Obermayer, K. (2004). New methods for the computer-assisted 3-D reconstruction of neurons from confocal image stacks. Neuroimage 23, 1283-1298.

Skiri, H. T., Rø, H., Berg, B. G., and Mustaparta, H. (2005). Consistent organization of glomeruli in the antennal lobes of related species of heliothine moths. J. Comp. Neurol. 491, 367-380.

Smid, H. M., Bleeker, M. A., Van Loon, J. J. A., and Vet, L. E. (2003). Three-dimensional organization of the glomeruli in the antennal lobe of the parasitoid wasps Cotesia glomerata and C. rubecula. Cell Tissue Res. 312, 237-248.

Stocker, R. F, Lienhard, M. C., Borst, A., and Fischbach, K. F. (1990). Neuronal architecture of the antennal lobe in Drosophila melanogaster. Cell Tissue Res. 262, 9-34.

Stopfer, M. (2007). Olfactory processing: massive convergence onto sparse codes. Curr. Biol. 17, 363-364.

Tanaka, N. K., Awasaki, T., Shimada, T., and Ito, K. (2004). Integration of chemosensory pathways in the Drosophila second-order olfactory centers. Curr. Biol. 14, 449-457.

Toga, A. W. (2002). Neuroimage databases: the good, the bad and the ugly. Nat. Rev. Neurosci. 3, 302-309.

Toga, A. W., and Thompson, P. M. (2001). Maps of the brain. Anat. Rec. 265, 37-53.

Van Essen, D. C. (2002). Windows on the brain: the emerging role of atlases and databases in neuroscience. Curr. Opin. Neurobiol. 12, 574-579.

Varela, N., Couton, L., Gemeno, C., Avilla, J., Rospars, J. P., and Anton, S. (2009). Three-dimensional antennal lobe atlas of the oriental fruit moth, Cydia molesta (Busck) (Lepidoptera: Tortricidae): comparison of male and female glomerular organization. Cell Tissue Res. 337, 513-526.

Vickers, N. J., and Christensen, T. A. (2003). Functional divergence of spa- tially conserved olfactory glomeruli in two related moth species. Chem. Senses 28, 325-338.

Vickers, N. J., Christensen, T. A., and Hildebrand,J.G. (1998).Combinatorial odor discrimination in the brain: Attractive and antagonist odor blends are represented in distinct combinations of uniquely identifiable glomeruli. J. Comp. Neurol. 400, 35-56.

Vosshall, L. B., Amrein, H., Morozov, P. S., Rzhetsky, A., and Axel, R. (1999). A spatial map of olfactory receptor expression in the Drosophila antenna. Cell 96, 725-736.

Vosshall, L. B., and Stocker, R. F. (2007). Molecular architecture of smell and taste in Drosophila. Annu. Rev. Neurosci. 30, 505-533.

Wilson, R. I., and Mainen, Z. F. (2006). Early events in olfactory processing. Annu. Rev. Neurosci. 29, 163-201.

Wong, A. M., Wang, J. W., and Axel, R. (2002). Spatial representation of the glomerular map in the Drosophila protocerebrum. Cell 109, 229-241.

Conflict of Interest Statement: The authors declare that the research was conducted in the absence of any commercial or financial relationships that could be construed as a potential conflict of interest.

Received: 05 December 2009; paper pending published: 18 January 2010; accepted: 26 January 2010; published online: 12 Febuary 2010.

Citation: Løfaldli BB, Kvello $P$ and Mustaparta $H$ (2010) Integration of the antennal lobe glomeruli and three projection neurons in the standard brain atlas of the moth Heliothis virescens. Front. Syst. Neurosci. 4:5. doi: 10.3389/neuro.06.005.2010

Copyright (c) 2010 Løfaldli, Kvello and Mustaparta. This is an open-access article subject to an exclusive license agreement between the authors and the Frontiers Research Foundation, which permits unrestricted use, distribution, and reproduction in any medium, provided the original authors and source are credited. 